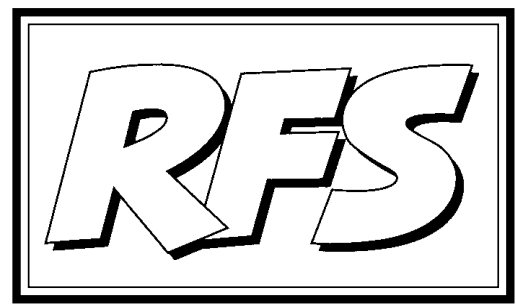

Revista de Fomento Social, 53 (1998), 567-574

\title{
XII Reunión del Grupo de Fomento Social
}

(Madrid, 28-29 noviembre 1998)

Ildefonso CAMACHO LARAÑA S.J. (*)

Una vez más el Grupo Fomento Social celebró su encuentro anual en la Casa de Espiritualidad de las Esclavas del Sagrado Corazón, en Madrid (c/. General Martínez Campos), este año bajo la coordinación de un nuevo secretario (el que firma esta crónica), ayudado por una comisión compuesta por Miguel Juárez (Universidad Comillas, Madrid) y Lluís Recolons (Migrastudium, Barcelona). El número de participantes se elevó a 32, entre los que se contaban tres jesuitas portugueses, uno italiano, uno chileno y el encargado del Secretariado Social de la Compañía de Jesús, P. Michael Czerny.

El tema de fondo escogido para este encuentro fue: «Pensamiento económico crítico, economía alternativa». Se dedicó también una parte del encuentro al

(*) Profesor de la Facultad de Teología de Granada y de la Facultad de Ciencias Económicas y Empresariales - ETEA, de la Universidad de Córdoba. 
estudio del documento «Características del apostolado social de la Compañía de Jesús» y a la función de este Grupo Fomento Social en el marco de esas orientaciones; como es costumbre, se presentaron además algunas comunicaciones.

\section{El tema de fondo: pensamiento económico crítico, economía alternativa}

Carlos Berzosa, catedrático de economía aplicada en la Universidad Complutense, presentó una ponencia con el título «Pensamiento económico crítico, economía alternativa». Definió la economía crítica como aquélla que milita contra la teoría económica dominante o contra el sistema vigente. Pero subrayó inmediatamente -y ésta quería ser como la tesis de su exposición-que en la confrontación histórica entre ortodoxia y heterodoxia, la ortodoxia ha ido cambiando, porque lo que en una época fue ortodoxia ahora es heterodoxia y viceversa. Para mostrar la exactitud de este punto de vista contrapuso los años del auge económico de la posguerra a la etapa actual que se inicia con la crisis de los años 70 .

En la posguerra el keynesianismo representaba la ortodoxia económica. Los keynesianos creían poseer los mecanismos esenciales para controlar la actividad económica. Los liberales eran los desfasados. El pensamiento radical surge -paradójicamente, en Estados Unidos- como cuestionamiento del keynesianismo. Aunque se trata de un movimiento heterogéneo, con más o menos presencia del marxismo, se puede considerar a Baran y Sweezy como los autores más representativos. La «Monthly Review» será el principal portavoz de esta corriente. Ante la constatación de que la desigualdad continúa, el poder económico se concentra y las desigualdades a nivel mundial se acrecientan, para estos autores el análisis económico no puede quedarse en agregados macroeconómicos (como la demanda agregada), sino que debe introducir factores sociales (esencialmente, las relaciones sociales). Es cierto que el capitalismo genera un gran excedente que necesita una demanda, pero ésta la encuentra en los países desarrollados en los gastos militares; en los países subdesarrollados este excedente, que también se produce, queda en manos de poca gente y no llega a invertirse en actividades productivas.

Mientras que en Europa, el pensamiento crítico está bastante vinculado a los partidos comunistas, de tendencia más bien dogmática, en los países subdesarrollados se orienta hacia la teoría de la dependencia. En ésta pueden distinguir- 
se dos ramas: una, marxista (representada por el propio Baran, Gunder Frank, T. dos Santos, Samir Amir); otra, que se desarrolla desde la CEPAL (Celso Furtado, Otto Sunkel, Fernando Henrique Cardoso, Faleto, Emmanuel). Estos autores vinculados a la CEPAL experimentaron un fuerte choque entre las ideas que habían recibido durante sus años de estudio en universidades anglosajonas y la realidad que encontraban al volver a sus propios países; sentían además un creciente rechazo hacia la insistencia monetarista del FMI y hacia la tendencia a identificar desarrollo con crecimiento. La teoría de la dependencia tuvo un fuerte impacto en el mundo occidental, antes de su declive posterior: es indudable su influjo en autores reformistas, como Ian Tinbergen, o en los trabajos de la Comisión Brandt.

Este panorama ha cambiado radicalmente en nuestros días, en un proceso que arranca de la crisis de los 70: porque ahora la ortodoxia liberal sustituye a la keynesiana, mientras que el keynesianismo tiene que ser defendido por los economistas radicales (los que antes lo habían criticado).

El neoliberalismo es una vuelta al pensamiento neoclásico apoyándose en Hayek y Friedman, que popularizaron la teoría de las expectativas racionales. En un principio se pensaba que sólo podía aplicarse bajo regímenes dictatoriales (el Chile de Pinochet). Thatcher y Reagan se encargaron de demostrar que no. Aplicaron la estrategia neoliberal de desinflar el papel del Estado, reducir el déficit público, desregular sobre todo el mercado laboral, combatir la inflación con políticas monetarias, facilitar la integración de las economías nacionales en la economía mundial. Se trata de un ataque furibundo al Estado de bienestar (o al Estado asistencial, en el caso de los Estados Unidos). La Sra. Thatcher se distinguió por su dureza con los sindicatos y por su clara política de privatizaciones, sobre todo en el sector servicios. En el caso de Ronald Reagan, se mezcló paradójicamente una política de fuertes gastos militares de corte keynesiano (su Iniciativa Estratégica le permitió superar la potencia nuclear soviética) con una drástica desregulación laboral.

El neoliberalismo es, en pocas palabras, un ataque en toda regla contra el keynesianismo, al que se culpa de todos los males de nuestras sociedades: a la solidaridad, típica del Estado de bienestar, se opone ahora la competitividad. Tan duro es este ataque, que la economía radical tiene ahora que salir en defensa del keynesianismo, al que en otro tiempo tanto criticó. Detrás de aquella crítica al keynesianismo existía el convencimiento de que había una alternativa

\section{CRONICA}


al capitalismo; hoy, este convencimiento se ha desvanecido...

Esta ortodoxia neoliberal también tiene una fuerte repercusión en el tercer mundo. En la propuesta que parece imponerse desde los años 80 se exige que sea el Sur el que se ajuste al Norte. Esa es la política seguida por las instituciones de Bretton Woods. Sólo en estos últimos meses parece desmoronarse uno de los ejemplos que siempre se aducía: el de los «tigres asiáticos». Porque ahora empezamos a comprender que el milagro no era tal, ni la política aplicada en ellos tan liberal como se decía...

¿Cabría resumir en pocas palabras la esencia de la heterodoxia económica? Quizás el denominador común a todas las corrientes que se incluyen aquí sería su fuerte sentido crítico frente a la coherencia formalista de los neoliberales, que seduce por su impresión de neutralidad científica. Esta actitud crítica se dirige contra la teoría y contra la realidad, contra todo intento de reducir el análisis económico al individuo, las preferencias y las utilidades. Porque el pensamiento crítico insiste en introducir las relaciones sociales (de poder, de dominación, etc.) que subyacen a los fenómenos económicos y son la fuente de desigualdades a todos los niveles. En este sentido, el mercado es el reflejo de esas relaciones sociales, lo que significa que no todos acceden a él en las mismas condiciones. Lo que está aquí en juego, en el fondo, es aceptar que la economía no es una ciencia pura y matemática, sino una ciencia social: en otras palabras, que las relaciones sociales han de ser objeto de la economía, y no sólo de la sociología o de la psicología.

A la exposición siguió un diálogo animado, en el curso del cual se tocaron variados temas. Se analizaron distintos aspectos de la evolución reciente de la Unión Europea, especialmente ante el giro político que supone la vuelta de los partidos socialdemócratas a muchos gobiernos de los países miembros; ¿puede esperarse de esta nueva coyuntura política una aplicación menos rigurosa del Pacto de Estabilidad, que permita un mayor crecimiento económico e incremento del empleo? Se comentaron también algunos extremos del llamado «pensamiento único» y la interpretación que se hace desde él del pretendido éxito económico de los «tigres asiáticos», subrayando algunas matizaciones derivadas de los últimos acontecimientos. La cooperación al desarrollo fue otro objeto de atención, comparándola con lo que es una beca para estudios: es una ayuda importante, pero no sirve de nada si el beneficiario no colabora con su trabajo. Por último, se subrayó el papel del pensamiento ecologista, de los Informes al 
Club de Roma y de los nuevos conceptos de desarrollo humano elaborados por el PNUD como elementos que enriquecen con otras perspectivas toda esta línea del pensamiento económico crítico.

\section{El documento Características del apostolado social de la Compañía de Jesús}

Una parte importante del encuentro de este año se dedicó al estudio del documento recientemente publicado Características del apostolado social de la Compañía de Jesús. Este documento no es todavía definitivo, pero recoge los frutos de un largo trabajo que se inició en 1995, en el que han participado jesuitas de todo el mundo. Un momento esencial de este proceso fue el congreso mundial que se celebró el Nápoles (Italia) en junio de 1997, en el que tomaron parte 160 jesuitas representantes de todos los países donde la Compañía está presente. El texto ahora disponible es aún provisional. Se espera que su aprobación definitiva se haga en el año 2000.

El estudio que se hizo del citado documento, bajo la dirección de Michael Czerny, Director del Secretariado Social de la Compañía de Jesús (Roma), tenía por objeto contribuir a una clarificación del apostolado social de los jesuitas en España. Este proceso, que se considera necesario después de los nuevos caminos abiertos en las últimas décadas, es la verdadera razón de ser de este documento: está concebido como un instrumento para animar el proceso de clarificación del apostolado social de los jesuitas.

Michael Czerny expuso el sentido último del apostolado social en la Compañía, así como la complejidad de actuaciones que pueden incluirse bajo esta denominación.

Los orígenes del apostolado social están en la misma Fórmula del Instituto, por medio de la cual fue aprobada la Compañía de Jesús por el Papa Paulo III: en ella se afirma que la Compañía es fundada para «atender principalmente a la defensa y propagación de la fe y al provecho de las almas en la vida y doctrina cristiana... reconciliar a los desavenidos, socorrer misericordiosamente y servir a los que se encuentran en las cárceles y en los hospitales, y ejercitar todas las demás obras de caridad, según que parecerá conveniente para la gloria de Dios y el bien común». Hay que esperar hasta la revolución industrial para que la Iglesia comience a descubrir que su misión de evangelizar ha de dirigirse, no sólo a los individuos, sino también a la misma sociedad en su conjunto, critican- 
do sus estructuras injustas, defendiendo los derechos humanos, exhortando a la gente a que transforme la sociedad a la luz del Evangelio. Estas orientaciones van impregnando también, sobre todo a lo largo del siglo XX, las actividades de los jesuitas en el campo social.

En este proceso es esencial el giro de la Compañía en su Congregación General 32 del año 1975, en consonancia con los cambios de la Iglesia a partir del Concilio Vaticano II: en ese momento la Compañía reformula su misión como «el servicio de la fe, del que la promoción de la justicia constituye una exigencia absoluta, en cuanto forma parte de la reconciliación de los hombres exigida por la reconciliación de ellos mismos con Dios». Esta tarea de servicio de la fe y promoción de la justicia se entiende como dos aspectos indisolublemente unidos de una única misión: más aún, ellos constituyen el «factor integrador» de todas las actividades de los jesuitas, algo que debe ser dimensión irrenunciable de cualquier tarea o actuación.

Veinte años más tarde, en la Congregación General 34 de 1995, esta perspectiva se ha ampliado con nuevas dimensiones: el servicio de la fe y la promoción de la justicia «no puede realizarse si, al mismo tiempo, no se cuidan las dimensiones culturales de la vida social y la manera como una determinada cultura se sitúa con respecto a la trascendencia religiosa».

Estas coordenadas (carisma fundacional y adaptación del mismo a las condiciones de nuestro mundo) sirven de marco para el apostolado social. Su objetivo específico es tender «a que las estructuras de la convivencia humana se impregnen y sean expresión más plena de la justicia y de la caridad» (NC 298), llevando así la justicia del Evangelio a la sociedad y a la cultura.

La expresión genérica apostolado social es rica en contenido. El adjetivo social apunta a toda la coexistencia humana en cuanto vivida, en cuanto cambiante, en cuanto estructurada y enculturada, en cuanto analizada o estudiada; lo social incluye lo político, lo cultural, lo religioso, etc., pero acentúa el impacto político o público de cualquier trabajo o actividad. El sustantivo apostolado alude a la misión, al testimonio, a la presencia redentora y liberadora de la Iglesia entre los hombres. En fin, la expresión apostolado social sugiere preocupación por los que sufren, por la injusticia y la pobreza. «Estrechamente ligado con la obra de evangelización», el apostolado social incluye «la transformación de las estructuras [sociales] en busca de la liberación tanto espiritual como material del hombre» y el «trabajar directamente con las personas mismas, con quienes son 
las víctimas de las injusticias de las estructuras y con quienes sobre éstas tienen cualquiera responsabilidad o influencia» (Congregación General 32, decreto 4, n. 40).

La expresión apostolado social pretende ser una denominación genérica capaz de englobar multitud de actividades que en distintos lugares reciben nombres diferentes: acción social, ministerios sociales, pastoral social, sector social, misión obrera, justicia social, misión popular, Cuarto Mundo, etc. Ninguna actividad o enfoque concreto está especificado o excluido. Para concretar más su significación en la Compañía suele distinguirse entre dimensión social (inherente a cualquier actividad) y sector social: dentro de éste pueden incluirse, tanto las instituciones («centros sociales de investigación, divulgación y acción») como la «acción social directa con y por los pobres» (NC 300).

En el diálogo que siguió a la exposición de M. Czerny se destacó la importancia de la elaboración de este documento, que algunos valoraban más que el mismo texto final: ha supuesto un esfuerzo de reflexión, de lectura común de los problemas, de convergencia de personas que trabajan en actividades y en líneas diferentes. El documento es extenso: su estilo es reflexivo, y dice muchas cosas que parecen obvias, pero que, en la práctica de cada día, de ninguna manera lo son. El documento es amplio en su concepción del apostolado social, precisamente para incluir a todas sus formas. Algunos temían que se fuese hacia una excesiva institucionalización del sector social; otros creían que una cierta institucionalización era necesaria como resorte para dinamizar la vida de los jesuitas y todas sus instituciones en esta línea.

\section{El Grupo Fomento Social y el apostolado social de la Compañía}

Toda la reflexión sobre el documento Características... tenía una indudable incidencia sobre el Grupo Fomento Social, que se reunía en este encuentro. Dicho Grupo nació en 1986 como una agrupación de jesuitas españoles que trabajan en ciencias sociales y en la acción social con un doble objetivo: el contacto, los intercambios periódicos y la cooperación entre ellos; las relaciones con otras organizaciones similares y con los jesuitas de dedicación paralela en otras partes del mundo.

En el curso de este diálogo hubo un acuerdo básico en torno a algunos puntos:

1) Se ve la necesidad de promover el fortalecimiento de la presencia 
institucional del sector social. Esta «presencia institucional» se entiende en un doble sentido: como una presencia colectiva, y no sólo individual y/o excesivamente dependiente del carisma de una persona; como una presencia ignaciana, es decir, que exprese lo específico de la espiritualidad y de la pedagogía ignaciana en sus objetivos, estilo y organización.

2) El Grupo Fomento Social debe seguir, en el sentido de que no se debería perder lo que ha conseguido en sus doce años de existencia; pero al mismo tiempo debe avanzar en líneas tales como una mejor conexión entre pensamiento y acción como dimensiones complementarias, una relación más explícita con las instituciones de la Compañía con incidencia en este campo (centros superiores, revistas, centros fe-cultura, etc.), una mayor presencia de laicos colaboradores en las obras de la Compañía, una mayor inserción en la red europea.

\section{Otros contenidos del encuentro}

En la sesión de la mañana del domingo día 29 hubo también tres comunicaciones, de otros tantos participantes en el encuentro: «Hacia un gobierno mundial» (Javier Gorosquieta, Universidad de Deusto) «La red jesuítica para el estudio de la globalización» (Josep Mària, Cristianisme i Justícia, Barcelona), «La ley de extranjería y su previsible reforma» (Daniel Izuzquiza, Madrid).

El encuentro concluyó con una breve asamblea estatutaria del grupo. Tras hacer una breve evaluación de su desarrollo, se propusieron temas para el año próximo. De entre los sugeridos fue elegido: «Las ONGD y la cooperación al desarrollo: reflexión crítica sobre sus fortalezas y debilidades». Se pidió además que este tema se planteara en relación con el voluntariado, que insiste más en la acción solidaria, pero a veces se resiste a una aproximación estructural a los problemas. 